\title{
Research on the Performance Management Problems in Local Governments' Administrative Service Centers and the Countermeasures
}

\author{
Li Ting, Geng Hong \\ College of Economics and Management \\ Nanjing University of Aeronautics and Astronautics, Nanjing 211106, China \\ Email: 1007885061@qq.com
}

\begin{abstract}
The construction of a service-oriented government has become a considerable trend of government transformation; and the administrative service center, as a major innovation of China's administrative system reform, not only represents a useful attempt made by the government at managing work performance, but also fully reflects the public's satisfaction with the government services. Although the quality and the level of public services in today's society have made significant progress compared to the past, it is still hard to meet the rapidly growing demands of the public, which triggered a lot of conflicts and contradictions between the two. With the continuous establishment and development of a service-oriented government, the ways to effectively manage the performance of administrative service centers, to solve the existing problems of performance management, to improve the efficiency of administrative service centers, and to deepen the process of the governmental reform have actually become very significant in reality. In this article, through analyzing the development of administrative service centers of local government performance management and the main problems, then provides some countermeasures and suggestions on improving the performance management of the local government's administrative service center.
\end{abstract}

Keywords: performance management, administrative service center, serviceoriented government, public service

\section{Introduction}

"The development of the country, the national culture inheritance, social stability, long-term sustainable economic development, and the comfortable and stable life of the people are, to some extent, inseparable with the quality and efficiency of the government's public service [1]." The performance management of the government is not confined to daily governmental affairs only. It also involves the administrative decision-making behaviors in the economic, cultural, political and other aspects. The management is realized through the analysis, measurement and evaluation of the behavioral effects by the government itself, or by other social organizations. Prior to the Sixteenth National People's Congress, China was still in a period of regulatory government which was under reform and development. In order to balance the modes of management and to develop social economy, Comrade Hu Jintao proposed at the 17th CPC National Congress that one of the major tasks today is to reform the existing government administration system and accelerate the construction of a service-oriented government [2], which is a new requirement raised by social reality on the government's management modes and its management concept in a new situation, signifying that the construction of a service-oriented government has 
nowadays become the new goal of the government's social management function transformation in China. The "service-oriented government" is a kind of vocabulary with Chinese characteristics in the process of the reform of Chinese government functions. It is not only a new concept in the field of government administration theory, but also an important product to explore the improvement of government management model [3]. As a management tool which can realize high efficiency of the government's performance management, the performance appraisal system plays a very important role in the government management system. The result of the performance management also indicates the service level of the government to a certain extent.

\section{Status Quo Analysis of local government administrative service center performance management}

In the late 1990s, with the reform and development of the administrative examination and approval system, and with a view to promoting people's understanding of governmental work as well as to strengthening the supervision over the work of civil servants, China's first administrative service center was established in Jinhua City, Zhejiang Province, thus ushering in a new era of China's administrative services. More than 20 years has passed, and the administrative service center has been booming, thriving and full of vigor and vitality in China. It grows in number and adopts more functions day by day and becomes more important among the governmental affairs. The establishment of the administrative service center can simplify the workflow and the formalities effectively, thus providing a wide range of satisfactory administrative services to the general public with the shortest time and at the lowest cost [4]. According to the "2010 National Experience Sharing Session on Further Promoting an Open Government and Enhancing Government Services", there are currently 2842 established administrative service centers in the 31 provinces/autonomous regions/municipalities of China. The grass-roots service agencies are 42,000 in total, $3 / 5$ of which has established a convenience service center [5]. The current administrative service center operation status is as follows:

\subsection{Civil service management mechanism}

In terms of the way of providing civil service, the administrative service center determines the way to serve based on the timeliness, the nature and other requirements of the application while helping to give full play to the functions of the integrated service platform. Whenever a civilian comes to the center for some service which requires the joint effort of more than two departments, the center would stick to the principle of "coordination, approval process standardization, and time-sensitive completion" while strengthening the interdepartmental cooperation between the integrated departments of the administrative service center and handling the work through parallel examination and approval, thus effectively enhancing the service effectiveness. Meanwhile, in accordance with the service requirements of "unified acceptance, application classification, specified person in charge, and time-sensitive completion", the staff at the administrative service center window would classify the applications according to their natures, and then adopt the corresponding work approach based on the special requirements of each application.

\subsection{Supervision methods}

In order to optimize the government services, some local administrative service centers in our country install staff members from the counties' supervision bureaus at the administrative service centers so as to set up complaint windows and the reception 
system. Meanwhile, a series of regulations are applied to the various departments, service windows and staff members stationed in the administrative service center, including completing the work within a given time period, pursuing liabilities, the first receptionist shouldering the responsibility, etc., thus striving to solve the problems of inefficient service, inadequate service, shirking responsibilities, etc. In addition, in order to further strengthen the supervision over administrative service center windows, a sub-center of the administrative efficiency and complaint center is set up in the administrative service center of the district, where it implements an efficiency monitor card system on the service windows of the administrative service center of the district. The efficiency monitor cards are filled out by the civilians who come to the service center for business. They evaluate and comment on the efficiency, service quality and other aspects of the responsible units or staff members.

\subsection{Mode of Approval}

After the departments are stationed in the administrative service center, they carry out unified and standardized management, and adopt a uniform organization name, nature and functions, as well as a uniform operating mechanism and evaluation mechanism. The public service function of the administrative service center are extended, and the scope of services, expanded. The center adheres to the principle of "early intervention, parallel advancing, vertical convergence and timely conversion", integrating the collection of utility fees, the recharging of transportation fees and other convenience services into the scope of government service system construction. At the same time, the responsibilities for administrative examination and approval and for public service matters which used to be scattered in different departments are now concentrated in one section. The approval sections are concentrated in a government service center while the matters to be approved are concentrated in the e-government platform.

\subsection{Publicity of governmental affairs}

In accordance with the Administrative Permission Law and other laws and regulations, the administrative service center gathers the administrative affairs, administrative examinations and approvals, public services, administrative charges and other matters or services that it is responsible for, and provides a concentrated "one-stop" service while making the procedures open. The operational mode is as follows: a service window accepts the request, and informs relevant personnel of the situation once and for all; the service will be completed in a one-stop manner within a reasonably given time period. In this way, regarding each entry of administrative examination and approval matters and public service matters in the service center, the legal and regulatory basis required for approval, the types of declaration materials, the specific procedures, the pledged time limit for completion, the charging standards, the results of the public service, etc. are made open to the public.

\section{Existing Problems on the Performance Management of Local Governments' Administrative Service Centers}

\subsection{Imperfect relevant laws}

Although the administrative service center has long been supported by the government, its legitimacy has not yet been recognized by the state law, which shows that our legal system is not sound enough [6]. The establishment of administrative service centers of local governments has a certain degree of legitimacy and provides support for the whole economic development. It provides the public with efficient and convenient service, but its lack of legal basis should be deemed as a big flaw. It is precisely because of the lack of effective legal basis that a lot of differences exist in 
the service center. Operational difficulties especially exist in the implementation of a variety of services, authorities, approvals, etc., which makes the work of the service center more difficult. Due to the lack of legal basis, the interpretation of the nature of administrative service centers varies from region to region. Some regions consider them as administrative units which are mainly responsible for administrative work; but in some places they are defined as institutions, and in some other places, it is only considered as a functional body instead of an official organization.

\subsection{Inadequate Public Participation}

\subsubsection{The communication channels are not unimpeded.}

The center does not currently have an effective communication channel, which has bad influences on the performance management effects. On the one hand, due to the lack of publicity, many people do not know that the center implements work performance management and therefore do not participate.

\subsubsection{The public participation is Limited.}

The goal of the center has always been working to the satisfaction of the people, and it has also actively set up the evaluation system so that the public can participate in the evaluation of staff members at the service windows. However, the actual situation is not satisfactory. The majority of the people are either reluctant to participate in the evaluation, or they retain their true views during evaluation, so the center can not get the real evaluation results.

\subsection{The establishment of administrative service centers and their management lack uniform norms}

The original intention of the local administrative service center was to promote the efficiency of administrative examination and approval work. However, although the construction of the administrative center has simplified the administrative examination and approval process to a certain extent, and has also improved the efficiency of some examination and approval work, it has not fulfill the original intention on the whole so far, and has been intervene by various stakeholders, which hinders the smooth development of the work of the center. Particularly, some functional departments of local governments take a variety of methods to resists the arrangement of the administrative examination and approval matters being entrusted to the administrative service center. They practically make up all the reasons and excuses because, on the one hand, departments of local governments want to hold on to their approval authority, especially when the matter is related to those projects that involve significant interests, the decisions on which are always made by the local government alone. Since the center cannot be authorized, the corresponding services cannot be carried out, thus seriously hindering the work of the local administrative service center. Therefore, the center is unable to provide standardized services for citizens or organizations in the lack of authority for examining and approving.

At present, the administrative service centers of local governments in China are not yet independent from the local government administrative system, and they are still substantially auxiliary bodies that help the governments with the matter of administrative examination and approval. They do not have real administrative examination and approval authority [7]. The funds required for the operation of the center and the salaries of staff members are paid by the corresponding government departments, which make the center unable to get rid of the control of government departments, and can only perform the functions of coordination and supervision. However, compared with the center, the functional departments possess more power, with which the center can not contend. So whenever the center and the functional 
departments do not see eye to eye with one another, generally the center's opinions would be ignored.

\subsection{The assessment program is imperfect.}

Firstly, the center has not yet decided upon a unified standard for the assessment of service windows. The root of the problem is that different windows have different responsibilities which require employees of different qualities and operational capacity. Since the requirements for the objects to be assessed are not the same, the assessment criteria cannot be unified. In addition, the center does not take a variety of evaluation methods to assess the staff members at the service window. It mainly depends on the employees' self-assessment, and the evaluation results and public evaluation only serve as a reference, making the evaluation results unable to represent the real performance of the staff.

Secondly, according to the current situation of the evaluation, the evaluation results of the windows are very close. The differences are slight. Therefore, during the campaign for star service and work models, an honor rotation system will have to be resorted. Driven by this result, the staff members at each service window can take turns to get the titles even if they do not work hard, thus making them lost the motivation to work hard, which seriously blemishes the value of performance management and assessment.

\section{Countermeasures and Suggestions on Improving the Performance Management of the Local Government's Administrative Service Center}

China's social development has entered a new period where difficulties and opportunities coexist. Finding a more reasonable path to development while achieving a reasonable and sustainable development of the administrative service center is not only related to the political reform objective of China's service-oriented government construction, but also related to the enhancement of status and role of the government in social management in the future. In this regard, we should improve the basic system and standardize the process as soon as possible, and clearly define the functions and status of the administrative service center through formulating relevant laws and regulations, thus providing legal basis for the center and regulating the system and procedures. The most important thing is to encourage local administrative service centers to explore innovative systems so as to make breakthroughs in service commitments, administrative commissions, quality management and other aspects, thus establishing a long-term mechanism of administrative services.

\subsection{Build up Interactive Channels between the Government and the Public}

The governance of modern society takes on the form of consultation and interactive management. The government is the server and coordinator of the community and the public. When providing public services, the public is not only the recipient of public services, but can also act as joint partners, participants, and supervisors of public services [8]. The service of administrative service centers emphasizes interactive management, which reflects that democratic participation and citizen participation is the driving force of the administrative service center construction and the reform of the government as a whole. As regards the development and perfection of the administrative service center in China, first of all, we should improve the level of political participation by citizens and foster the citizens' sense of participation so as to give full play to their dominant position in the political life of the country. Second, we should continuously perfect each regulation and rule related to the actual service. In this way, we can further increase the openness degree of administrative affairs and 
guarantee the citizens' right to know. While expanding the channels of citizen participation, we should effectively learn from the management experience of the private sector and regard citizens as customers which should be treated with due respect. In this way, we can urge the front-line public service providers to enhance their service levels. In addition, we ought to introduce the "customer" concept and methods advocated by the "entrepreneur" type of governments into the government's administrative management. For example, we should manage the overall quality and the relationship with customers in order to establish new and better relations between government and citizens. Finally, through the introduction of the citizen satisfaction evaluation mechanism, satisfaction evaluations regarding the objects of service can be carried out, thus establishing good interactive relationship between the administrative service center and the public and realizing the people-oriented and service-oriented goal of the center.

\subsection{Improve the Incentive Mechanisms and Arouse the Work Enthusiasm of the Staff}

With the development of the administrative service center, the government should pay more attention to the development of the assessment system and the management measures. Strict system requirements can gradually reduce the service window staff members' sense of identity and belonging to the administrative service center while completing the high-intensity workload. Over time, this will lower the staff's conformity degree with the center's rules and regulations, and as a result, the service level and the professional level will not meet the requirements and standards. In addition, the existing performance management system lacks an effective incentive mechanism and is unable to rekindle the staff members' work enthusiasm from the complex work. Therefore, improving the incentive mechanism can effectively arouse the enthusiasm of the staff. To develop the incentive mechanism, we should first of all make full investigations and studies, and refer to the incentive mechanisms of enterprises while combining them with the characteristics of administrative service center itself. We should also fully listen to the reasonable requirements of the staff so as to develop a scientific and reasonable incentive mechanism. Secondly, we should take the the reasonable requirements of the staff members who work at service windows as the point of departure, and prioritize the development of the administrative staff, the basic requirements of each position, and the future development of the staff members as we develop the incentive mechanism - a mechanism which effectively arouses the enthusiasm of the staff while giving fuel to development, making sure that the staff are highly competitive each time they are rewarded. Finally, we should change the staff's work attitude by improving the working environment and work atmosphere while providing them with humanoriented management and humanistic care.

In addition, we should implement a full range of work supervision over the staff members through the network monitoring mechanism. The staff members should be graded, assessed and supervised in ways of public evaluation, department supervision, online assessment, etc. The evaluation results should be appraised through comparison and publicized. Reasonable rewards should be given in a timely manner while notices of necessary criticisms ought to be circulated among the staff. Also, the results of assessment should be included in the personal file so as to effectively arouse the enthusiasm of the staff member.

\subsection{Improve the Management System of the Administrative Service Center}

Each one's responsibilities and authorities should be clearly defined during the operation of the administrative service center. First of all, we should fully authorize 
the administrative center to perform administrative functions. The original functional department where the staff member was from is only responsible for sending the staff member to the service window of the administrative service center. They should not be given the right to directly interfere with the staff member's work even if they do not approve of it. Only when the staff member encounters problems can they provide error correction and guidance. It is the administrative service center that should be responsible for the daily management work; and it should also give rightful amount of authority for personnel assessment to the supervisors so as to improve the quality of management. Second, the responsibilities of the central department and the functional departments should be clearly defined. Once authorized, they are not to be interfered with. After authorized by the original functional departments, the administrative service center should be entirely and solely responsible for the administrative examination and approval management. In this way, the relationship between the functional departments and the administrative service center can be straightened out. Once the relationship is straightened out, we should establish joint mechanisms between all the departments, which allows us to firstly determine the work procedures and management methods of each service and then determine the respective responsibilities of each department, finally putting all the responsibilities in place. This hierarchical management can greatly enhance work efficiency through departmental collaboration. With such management, the operating costs are reduced, responsibilities and authority more clear-cut, and the level of service improved. The coupling mechanism between departments can improve the operation of the administrative service centers, and strengthen the financial and personnel management of the administratie service center from the legal angle. It can also establish and improve the administrative service center's operating mechanism, and ultimately realize the one-stop service mode [9].

\subsection{Improve the Center's Performance Appraisal Mechanism}

The service evaluation system should be established and improved. Through the evaluation instrument, advice box, telephone and other forms, we should establish the multi-channel service evaluation system in full range for the staff members and their service windows. The outstanding ones should be encouraged while the ones who lag behind should be spurred. Meanwhile, we should refer to the assessments made by the objects of government service as an important basis for the evaluation of the staff members at the service window.

A scientific evaluation index system should be established. A set of scientific, sound and strongly applicable evaluation index system brings positive incentives. By adopting various forms of evaluation tools, the Performance evaluation can determine the evaluation criteria, and guarantee that the whole evaluation process is fair and open, which is the fundamental factor of the success of government performance management [10]. The evaluation index system is the key factor for the government to improve the public service level and the service quality. It is also the key factor to develop public administration. Before developing the evaluation index system, the most critical and most central tasks are to be clearly aware of the objectives of the evaluation, to follow the guidance of enterprises' performance evaluation index, to develop an evaluation index system which is in line with the development of the center while following the active lead of the evaluation objectives. In this way, the staff's enthusiasm for work can be actively aroused, and each person's value in the position can be fully developed. The evaluation should be carried out in light of department rules and regulations, the content of service, the service requirements, and the results of appraisals through comparison will be released daily, monthly and 
yearly. Meanwhile, we should attach due importance to a variety of good proposals from the public, and integrate public satisfaction into the evaluation index. A complete set of evaluation index system is not to be formulated at random. It takes continuous trials, practices, the absorption of good experience and the removal of indicators which are unfitting for the development of the administrative service center. Therefore it is gradually developed. Meanwhile, the full support of the staff is indispensible to achieve continuous improvement of the organization's performance.

\section{References}

[1]Xia Shuzhang. Public Service. Administrative Management of China, 2003, (3): 16.

[2]Xinhua News Agency. Hu Jintao's Report at the Seventeenth Party Congress. http://news.xinhuanet.com/newscenter/2007-10/24/content_6938568_5.htm, 2007-1024

[3]Zhang Kangzhi. Grasp the theoretical direction of service government. People forum, 2006(5).

[4]Yu Keping. The Innovations of Chinese Local Governments. Social Science Academic Journal, 2002:10

[5]Let the People Know and Invite Them to Participate: A Review on The General Situation of the Publicity of National Governmental Affairs

[6]Feng Gguang. Play the role of administrative service center in the construction of service oriented government. Economy of Tianjin, 2008(8):41-42.

[7]Jin Zhan. The position and function of government service center in the construction of service oriented government. Wumeng tribune, 2009(5):53-63.

[8]Sheng Mingke. The practice and development trend of urban government performance management in western countries--- The basic countermeasures to promote the performance management of urban government in China. Administrative forum, 2011(4):43-47.

[9]Peters. P.G. (2013) The future of governing: Four models. [Wu A.M \& Xia H.T Trans]. Beijing: China Renmin University Press.

[10]Seok-Hwan lee. A Study on Application in the Public Sectorr Focused on the Case of Bucheon City, Journal of Public Adminis-tration of Korea [J]. Vol. 40, Nol, 2006: 135. 